\title{
The life cycle of an organization in a changing economic environment
}

\author{
Evgeniya Eliseeva ${ }^{1,2, *}$ and Angela Mottaeva ${ }^{3}$ \\ ${ }^{1}$ National University of Science and Technology "MISiS", 119049, Moscow, Leninsky, 4, Russia \\ ${ }^{2}$ Financial University under the Government of the Russian Federation, 125993, Moscow, \\ Leningradsky, 49, Russia \\ ${ }^{3}$ Moscow State University of Civil Engineering, 26 Yaroslavskoye Shosse, Moscow, 129377, Russia
}

\begin{abstract}
The concept of "life cycle" is used by an organization to plan a certain sequence of changes in the current state and maintain its position in the market in the future. In the theory of the life cycle of the organization's position in the market, it is emphasized that the development of an enterprise occurs according to an algorithm common to all organizations. However, the issues of manifestation of life cycle stages in a changing economy are ambiguous. There are no clearly established and regulated values of indicators that guarantee the maintenance of the position of organizations at the stages of their existence. The aim of the study is to substantiate the methodology for determining the stage of the life cycle of an organization for the development or adjustment of the strategic policy of its development. The study revealed that the assessment of the organization's potential is carried out on the basis of groups of indicators and factor coefficients established and recommended for use in Russian and international practice. As a result of the study, it was proposed to use the factorial integral indicator of the economic assessment of the enterprise, which allows the current position of the enterprise in the current economic situation and planning its activities in the future.
\end{abstract}

\section{Introduction}

In the current changing economic conditions, new organizations are formed daily. At the same time, every day hundreds of organizations are permanently liquidated. More flexible and stable organizations change and adapt, which contributes to the continuation of their activities, dependent ones disappear. There are organizations that are developing faster than others and are building their potential better than similar ones. It is recommended to determine the stage of development and the current location of the enterprise, to assess the compliance of the chosen strategy with the financial policy of the organization and the stage of its formation. Therefore, the concept of "life cycle" of an enterprise is used to plan a certain sequence of changes in the current state and to maintain its position in the market in the future. In the theory of the life cycle of the organization's position in the market, it is emphasized that the development of an enterprise occurs according to a scheme common to

\footnotetext{
${ }^{*}$ Corresponding author: Evgeniyae@mail.ru
} 
all organizations. This allows predicting probable crisis situations, develop preventive measures, justify management decisions on the use of resources and financial instruments to minimize possible undesirable situations.

Analysis of the enterprise as an independent economic system and the determination of the steps of its life cycle allow predicting the future characteristics of the organization. Which is reflected in the optimization of key indicators and improved economic results. The issues of manifestation of life cycle stages in a changing economy are ambiguous. There are no clearly established and regulated values of indicators that guarantee the maintenance of the position of organizations at the stages of their life cycle. Therefore, the question of the need to analyze and predict the life cycle of the enterprise is relevant. The applied areas of development should correspond to the level of the organization's current market position. To adjust its tasks, the enterprise uses calculation, analytical and graphical methods to determine the development trends of the company based on the theoretical foundations of the life cycle. It allows adjusting the tasks of the organization. The practical significance of the work lies in the analysis and development of proposals for the transition of an enterprise by stages of its activity.

\section{Materials and Methods}

The methodological basis of the study is based on normative and specialized sources of information on the analysis, assessment and development of proposals for moving an organization through the stages of its life cycle.

The life cycle activity diagram allows planning changes that correct and completely change the position of the organization at any stage of development. When determining at what stage the enterprise is, it is important to assess its own financial sources and the possibility of attracting financing from outside. Determination of the stage of the life cycle of an enterprise also contributes to the timely identification of negative consequences that await the organization at the next stage and to prevent their occurrence. If the transition to critical stages for the enterprise is inevitable, it is necessary to develop measures to minimize possible negative consequences [1].

The theory of life cycles of an enterprise's position in the market is based on an analogy with the life of biological objects. The life cycle of an organization includes the following stages:

1) developing an idea, creating an organization, entering the market and formation;

2) growth of potential, market position and image;

3) reaching the maximum of the development, maturity, market visibility;

4) decrease in demand and activity, gradual loss of potential;

5) either bankruptcy, liquidation, or revival.

The main stages of the possible movement of an organization through the stages of its life cycle are shown in Figure 1.

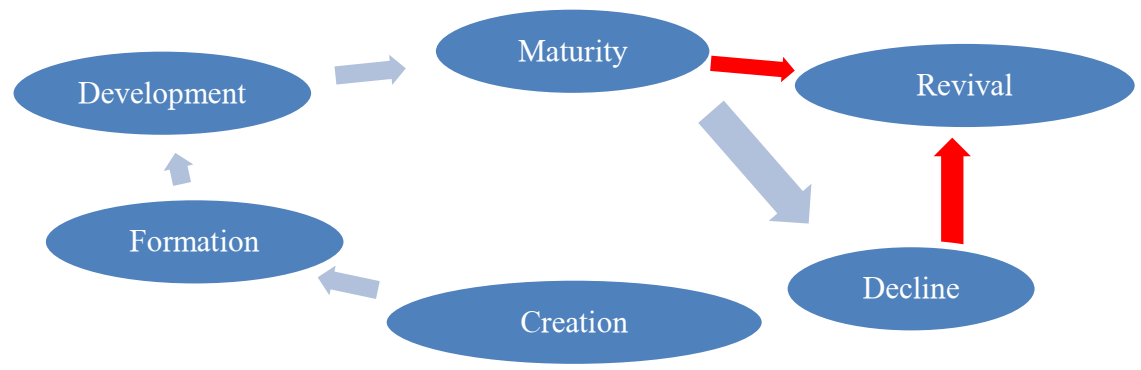

Fig. 1. The life cycle of the organization. 
The sequence, as well as the content of each stage of the organization's activities, has its own principles and characteristics, takes into account the existing and potential opportunities, taking into account risk factors, and involves the development of its acceptable financial policy.

At the first stage of creation, the company builds a simple organizational structure. Entering the market requires sufficient effort and is associated with the study of consumer demand and expectations from the products and services produced; collection and analysis of information about the intentions and potential of competitors, determination of their strengths and weaknesses [2]. This is the basis for developing our own strategy and creating an internal mechanism for making managerial decisions to attract all types of resources from our own and borrowed sources, creating a motivation system. The creation stage involves the search for like-minded people, the development and testing of ideas, legal registration, selection of resources, and the creation of a project product. The formation of the organization is caused by the personnel who is interested and sharing the ideas of the organization [3].

In the future, the enterprise becomes successful. There is a growth in potential, the development of image policy and consolidation of positions in the market [4]. The organization is increasing its profits, the company is developing, new divisions are being organized, business processes are becoming more complicated, methods and ways of management are improving, the range and volume of products is increasing. The enterprise becomes self-sufficient and can function without significant external funding. The organization's management system is changing: the business owner is engaged in strategic planning, delegating the solution of tactical tasks to middle managers [5]. The business processes of the organization take on a formalized form, the basis of the organizational corporate culture is formed [6]. It is possible to invite third-party professional managers or consultants and transfer certain areas of management to them. Difficulties may arise at this stage due to the unwillingness of the business owner to delegate authority [7]. This can slow down processes.

The period of stabilization, reaching the maximum of its development, maturity, perceptibility in the market occurs due to the formalization of roles and increased efficiency. The main resources of the organization are concentrated on internal efficiency [8]. The organization's efforts are aimed at maximizing profits in a highly competitive environment. During the maturity stage, great emphasis is placed on cost control. Management processes are slowing down. Decisions are made reasonably and carefully analyzed. The goal of this life stage is to maintain the won positions in the market. Risky projects are not accepted, the innovative potential of the organization does not develop.

On the decline in the vitality of an organization, its competitiveness decreases. The company strives to find new areas in the market. Turnover of employees and the growth of internal conflicts are possible and, as a result, a decrease in profitability. The enterprise is forced to apply the mode of cost-saving, cost optimization [9, 10]. Depending on management decisions and the results of stabilization of the situation, the organization can move to the stage of revival or attenuation. Unfortunately, the revival phase is not always feasible.

In special sources of information, there is no single point of view on the sequence and classification of steps in the life cycle of an enterprise. But there is commonality with the main elements of a person's life path (goal, method of organization).

In Russian practice, groups of coefficients are recommended to assess the financial condition and possible potential. World practices developed classifications of projections for assessment, for example, the Norton-Kaplan balanced scorecard. When forming its own factorial integral system, the enterprise is guided by the principles: indicators should be 
multifunctional, have an interpretation in time, be comparable and interconnected with each other.

The integral factor system includes the values of the absolute indicators of the economic activity of the organization. The criteria for selecting indicators in a factor system is the ability to use accounting data and internal information about the enterprise resources.

When analyzing an enterprise, all indicators characterizing economic activity are interconnected and depend on each other [11]. Therefore, the indicators included in the overall integrated assessment reflect the actions related to financial capabilities. To analyze the economic state of an enterprise, the following system of interrelated elements can be used [12]:

1) resulting indicators for a certain period (proceeds from the sale of products and services; profit; volume of sales of products and services in kind; costs and their structure; indicators of resource turnover and their profitability);

2) monetary indicators (liquidity, creditworthiness, self-financing);

3) market indicators (value and structure of assets, the number of employees, the cost of the organization, the dynamics of the exchange rate and return on shares, investments, market share);

According to the substantiation of the methodology, the factorial integral indicator is determined by the formula

$$
\Phi y=\Sigma \mathrm{pi} \cdot \Delta \mathrm{Cj}
$$

where Фy - factor integral indicator of the economic condition of the organization, unit fraction; pi - the weighting factor of each factor affecting the sustainability of the organization, unit fraction; $\Delta \mathrm{Cj}$ - point assessment of the value of each factor, point.

The factor integral indicator is determined and considered in dynamics and allows determining at what stage of the life cycle the enterprise is [13].

\section{Results}

The practical application of the proposed method for determining the life cycle of an organization was considered using the example of a Russian metallurgical enterprise that produces high quality products for the electric lamp and cable industries, instrument making, automotive industry, organizations for the production of batteries and chemical power supplies, etc. [14].

The factors affecting the economic situation of the enterprise are the coefficients presented in table 1 [15].

Table 1. Factors affecting the sustainability of the organization, in unit fractions.

\begin{tabular}{|l|c|c|}
\hline \multirow{2}{*}{ Factors } & \multicolumn{2}{c|}{ Factor value } \\
\cline { 2 - 3 } & recommended & actual \\
\hline 1 Asset mobility & 0.4 & 0.05 \\
\hline 2 Mobility of current assets & 0.1 & 0.05 \\
\hline 3 Provision of stocks & $0.8-1$ & 0.1 \\
\hline $\begin{array}{l}\text { 4 Provision of current assets with own circulating } \\
\text { assets }\end{array}$ & $\geq 1$ & 0.05 \\
\hline 5 Coverage of borrowed funds by equity & $\geq 0.7$ & 0.1 \\
\hline 6 Maneuverability of equity & $0.2-0.5$ & 0.15 \\
\hline 7 Financial sustainability & $\geq 0.6$ & 0.1 \\
\hline 9 Autonomy & $\geq 0.5$ & 0.2 \\
\hline 9 Financial leverage & $\leq 2$ & 0.2 \\
\hline
\end{tabular}


The column "Actual value of the factor" of Table 1 presents the average value of the factors for 3 years. Using the dynamics of the values of these factors, depending on the model of further development created at the metallurgical enterprise, the factorial integral indicator of the economic condition of the organization was determined, and a rating was compiled in points, taking into account the trends of change (Table 2).

Table 2. Assessment of the dynamics of factorial integral indicators of economic stability, in points.

\begin{tabular}{|c|c|c|c|c|}
\hline \multirow{2}{*}{$\begin{array}{c}\text { Value of indicators } \\
\text { for the planned } \\
\text { development } \\
\text { models }\end{array}$} & \multicolumn{3}{|c|}{$\begin{array}{c}\text { Changes in the factorial integral indicator of } \\
\text { the economic state of the enterprise in } \\
\text { dynamics }\end{array}$} & \multirow[t]{2}{*}{$\begin{array}{c}\text { Final score } \\
\text { (point) }\end{array}$} \\
\hline & for $\mathrm{N}$ year & for $(\mathrm{N}-1)$ year & for $(\mathrm{N}-2)$ year & \\
\hline Model 1 & $4+$ & $4+$ & $4+$ & $3(0)$ \\
\hline Model 2 & $7-$ & $4+$ & A+ + & $2.5(0.5)$ \\
\hline Model 3 & $\nabla-$ & $\nabla-$ & A+ & $2(1)$ \\
\hline Model 4 & $4+$ & $4+$ & $\nabla-$ & $1(2)$ \\
\hline Model 5 & $4+$ & $\nabla-$ & $\nabla-$ & $0.5(2.5)$ \\
\hline Model 6 & $\nabla-$ & $\frac{1}{t}-$ & $\downarrow-$ & $0(3)$ \\
\hline
\end{tabular}

We accept that with positive dynamics for factors $1-8$, their point score increases from 0 to 3 points. If the value of the factor changes, but it does not correspond to the standard value, 1.5 points are awarded. For factor 9, the "financial leverage ratio", a positive trend is considered to be its decrease. Then the growth of the financial leverage ratio is estimated as 0 points, the decrease - 3 points. This factor 9 is fundamental. Therefore, the scores determined depending on its rate of fluctuation are shown in table 2 in brackets.

The values of the factorial integral indicators of the economic state of the organization obtained according to the situations planned at the enterprise are ranked by the stages of the life cycle. The ranking methodology for the considered object of the study, a Russian metallurgical enterprise, is shown in Figure 2.

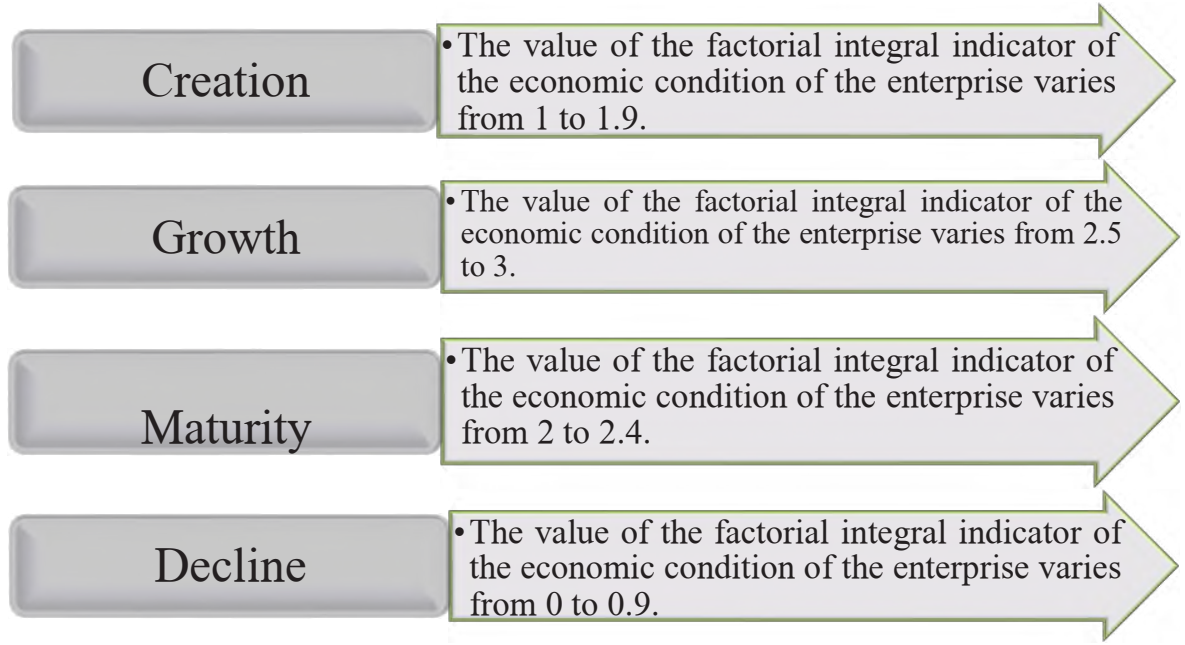

Fig. 2. The value of the factor integral indicator of the economic state of the enterprise when determining the step of the organization's life cycle.

After conducting a comprehensive analysis of the economic results of the operation of the research object, a decrease in the dynamics of proceeds from sales, the absolute liquidity ratio, and profitability indicators was obtained. The enterprise has low indicators of labor productivity and capital productivity, which is reflected in the capital-labor ratio. The result of the general economic assessment of the enterprise is shown in Figure 3. 
The obtained value of the factorial integral indicator of the economic state shows that the enterprise-object of the study is at the stage of decline $[16,17,18,19]$. The metallurgical enterprise needs to undertake a new strategy and objectives that will help it return one step back in the life cycle (Figure 3).

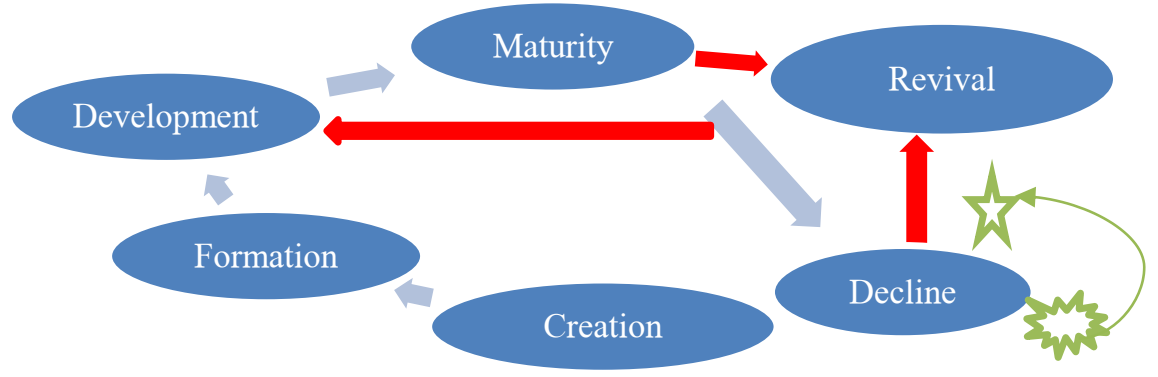

Fig. 3. The results of practical application of the proposed methodology using the example of a metallurgical enterprise.

\section{Conclusions}

The current changing economic situation directs organizations to timely and thoroughly monitor their condition in order to advance management decisions. The problem is that enterprises, striving to increase sales volumes, do not always focus on the dynamics of their development and position. Organizations pay more attention to the adopted main indicators of the analyzed period, but do not trace them in the dynamics of the life cycle activities.

In this study, to assess the life cycle of an enterprise, it is proposed to use an integral factor indicator. It is assumed that the organization independently determines the fundamental parameters for the analysis and assessment of its activities, including the resulting, monetary and market indicators. To include the factors established by the enterprise for assessing its well-being, it is recommended to rank them and translate them into a point assessment. This allows identifying the strengths and weaknesses of the organization and determining its position in the stages of the life cycle.

The practical application of the methodology for determining the life cycle of an organization proposed in the study was considered using the example of a Russian metallurgical enterprise. To obtain the result, the factorial and complex integral indicators were assessed for three years, the enterprise resources were additionally analyzed, the stage of the life cycle of the enterprise-object of the study was determined.

The economic attractiveness of the study lies in the focus of the organization not only on improving its economic performance, but also on revising its goals and objectives in order to return to a higher stage in the life cycle and retain market share.

\section{References}

1. Modern Entrepreneur: Taxes and Business Accounting, https://spmag.ru/articles/klassifikaciya-aktivov.

2. A. Sergeev, L. Akhmetshina, K. Grabovyy, E3S Web of Conferences 110, 02153 (2019)

3. N.S. Khoroshavina, A.V. Sharkova, O.N. Vasilyeva, O.V. Borisova, K.O. Sokolov, Espacios 39, 10-20 (2018) 
4. E. Eliseeva, 19th International multidisciplinary scientific GEOconference SGEM 2019, 307-316 (Albena, Bulgaria, 2019)

5. A.V. Aleksakhin, E. Eliseeva, L. Kostygova, I. Zaytsev, Y.V. Aleksakhina, 9th International Conference on Manufacturing Science and Education, MSE 2019 MATEC Web Conf. 290 (Sibiu, Romania, 2019)

6. L. Akhmetshina, A. Mottaeva, E3S Web of Conferences 210, 13034 (2020)

7. ISO 9004 -2010. Management for achieving sustainable success of the organization. The approach based on quality management, http://docs.cntd.ru/document/gost-r-iso9004-2010

8. I. Muradov, E. Sidorova, 18th International multidisciplinary scientific GEO conference SGEM 2018 (Albena, Bulgaria, 2018)

9. Y.V. Morozyuk, A.V. Sharkova, I.A. Merkulina, O.N. Vasilyeva, Journal of Environmental Management and Tourism 8(3), 507-515 (2017)

10. Y. Kostyukhin, 19th International multidisciplinary scientific GEOconference SGEM 2019, 131- 138 (Albena, Bulgaria, 2019)

11. L. Kostygova, 18th International multidisciplinary scientific GEO conference SGEM 2018 (Sofia, Bulgaria, 2018)

12. E. Eliseeva, 19th International multidisciplinary scientific GEOconference SGEM 2019, 299-306 (Albena, Bulgaria, 2019)

13. L. Akhmetshina, A. Mussina, S. Izmaylova, IOP Conf. Series: Earth and Environmental Science 403, 012168 (2019)

14. Official site of the Shchelkovo Metallurgical Works JSC http://оао-щелмет.рф/

15. E. Anoshkina, E. Markovskaya, A. Mottaeva, As. Mottaeva, E3S Web of Conferences 210, 13022 (2020) https://doi.org/10.1051/e3sconf/202021013022

16. I. Muradov, 19th International multidisciplinary scientific GEO conference SGEM 2019 (Albena, Bulgaria, 2019)

17. A. Mottaeva, J. Stepanova, N. Meshkova, G. Semenova, European Journal of Sustainable Development 10(1) (2021) Doi: 10.14207/ejsd.2021.v10n1p705

18. E. Ganebnykh, O. Lezhnina, J. Zhukova, V. Kashintseva, E3S Web of Conferences 210, 10008 (2020) https://doi.org/10.1051/e3sconf/202021010008

19. E. Ganebnykh, O. Fokina, V. Lukinov, E3S Web of Conferences 135, 04049 (2019) https://doi.org/10.1051/e3sconf/201913504049 